


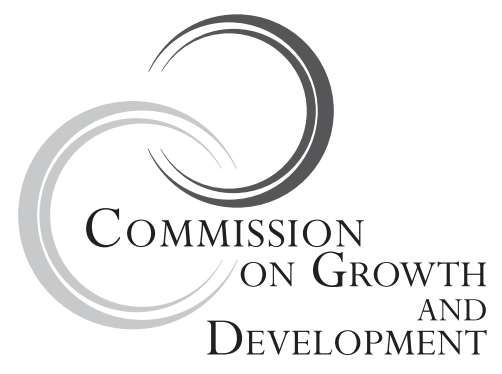

\section{Macro Crises and Targeting Transfers to the Poor}

Ravi Kanbur

Australian Government

DFID

Dutch Ministry

of Foreign Affairs

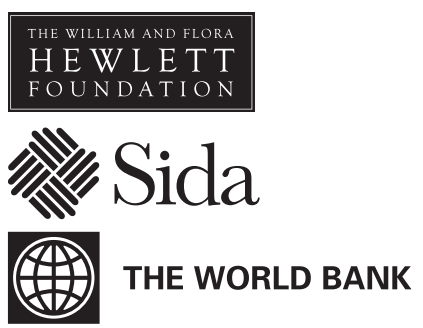


(C) 2010 The International Bank for Reconstruction and Development / The World Bank

On behalf of the Commission on Growth and Development

1818 H Street NW

Washington, DC 20433

Telephone: 202-473-1000

Internet: www.worldbank.org

www.growthcommission.org

E-mail: info@worldbank.org

contactinfo@growthcommission.org

All rights reserved

123413121110

The Commission on Growth and Development is sponsored by the following organizations:

Australian Agency for International Development (AusAID)

Dutch Ministry of Foreign Affairs

Swedish International Development Cooperation Agency (SIDA)

U.K. Department of International Development (DFID)

The William and Flora Hewlett Foundation

The World Bank Group

The findings, interpretations, and conclusions expressed herein do not necessarily reflect the views of the sponsoring organizations or the governments they represent.

The sponsoring organizations do not guarantee the accuracy of the data included in this work. The boundaries, colors, denominations, and other information shown on any map in this work do not imply any judgment on the part of the sponsoring organizations concerning the legal status of any territory or the endorsement or acceptance of such boundaries.

All queries on rights and licenses, including subsidiary rights, should be addressed to the Office of the Publisher, The World Bank, 1818 H Street NW, Washington, DC 20433, USA; fax: 202-522-2422;

e-mail: pubrights@worldbank.org.

This paper was prepared for the Commission on Growth and Development. It was first published in the Journal of Globalization and Development (Volume 1 Issue 1, January 2010). (C 2010 The Berkeley Electronic Press.

Cover design: Naylor Design 


\section{About the Series}

The Commission on Growth and Development led by Nobel Laureate Mike Spence was established in April 2006 as a response to two insights. First, poverty cannot be reduced in isolation from economic growth-an observation that has been overlooked in the thinking and strategies of many practitioners. Second, there is growing awareness that knowledge about economic growth is much less definitive than commonly thought. Consequently, the Commission's mandate is to "take stock of the state of theoretical and empirical knowledge on economic growth with a view to drawing implications for policy for the current and next generation of policy makers."

To help explore the state of knowledge, the Commission invited leading academics and policy makers from developing and industrialized countries to explore and discuss economic issues it thought relevant for growth and development, including controversial ideas. Thematic papers assessed knowledge and highlighted ongoing debates in areas such as monetary and fiscal policies, climate change, and equity and growth. Additionally, 25 country case studies were commissioned to explore the dynamics of growth and change in the context of specific countries.

Working papers in this series were presented and reviewed at Commission workshops, which were held in 2007-08 in Washington, D.C., New York City, and New Haven, Connecticut. Each paper benefited from comments by workshop participants, including academics, policy makers, development practitioners, representatives of bilateral and multilateral institutions, and Commission members.

The working papers, and all thematic papers and case studies written as contributions to the work of the Commission, were made possible by support from the Australian Agency for International Development (AusAID), the Dutch Ministry of Foreign Affairs, the Swedish International Development Cooperation Agency (SIDA), the U.K. Department of International Development (DFID), the William and Flora Hewlett Foundation, and the World Bank Group.

The working paper series was produced under the general guidance of Mike Spence and Danny Leipziger, Chair and Vice Chair of the Commission, and the Commission's Secretariat, which is based in the Poverty Reduction and Economic Management Network of the World Bank. Papers in this series represent the independent view of the authors. 


\section{Acknowledgments}

This paper was prepared for the Commission on Growth and Development. It was first published in the Journal of Globalization and Development (Volume 1 Issue 1, January 2010). (C) 2010 The Berkeley Electronic Press. 


\begin{abstract}
A central question for policy makers concerned with helping the poor through a macro crisis is how to target scarcer resources at a time of greater need. Technical arguments suggest that finer targeting, through tightening individual programs or reallocating resources towards more tightly targeted programs, uses resources more efficiently for poverty reduction. These arguments survive even when the greater informational costs and the incentive effects of finer targeting are taken into account. But political economy arguments suggest that finer targeting will end up with fewer resources allocated to that program, and that looser targeting, because it knits together the interests of the poor and the near-poor, may generate greater resources and hence be more effective for poverty reduction despite being "leakier." Overall, the policy advice to tighten targeting and to avoid more loosely targeted programs during crises needs to be given with considerable caution. However, the advice to design transfer systems with greater flexibility, in the technical and the political economy senses, is strengthened by the arguments presented here. The case for external assistanceto design flexible transfer systems ex ante and to relieve the painful tradeoffs in targeting during a crisis - is also shown to be strong.
\end{abstract}





\section{Contents}

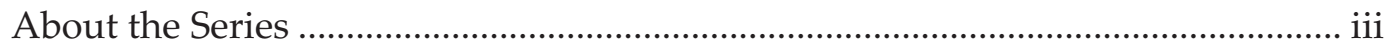

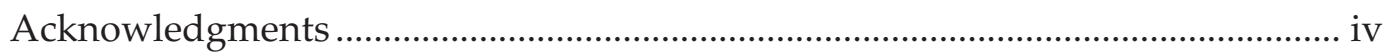

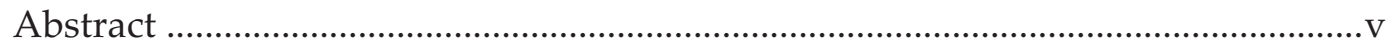

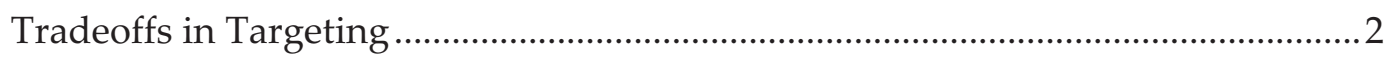

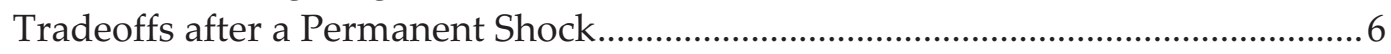

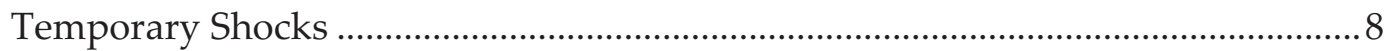

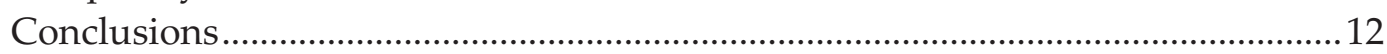

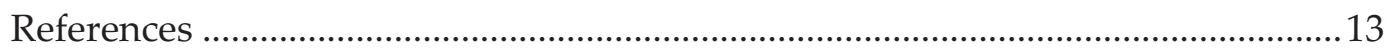





\title{
Macro Crises and Targeting Transfers to the Poor
}

\author{
Ravi Kanbur ${ }^{1}$
}

The discourse on the current global macro crisis, as happens during all such crises, has highlighted the plight of the poor in coping with the consequences. ${ }^{2}$ Of particular significance is the use of existing policy instruments, and possibly the design and implementation of new ones, to protect the poor during the crisis and to maintain their capacity to benefit from the rebound when it comes. There is, of course, a large literature on redistribution and targeting the poor. The objective of this paper is to relate this general literature to issues that arise during macro crises and to ask whether the same principles can be used to illuminate the tradeoffs faced by policy makers as they address the consequences of the crisis for the poor. In particular, the central issue considered is whether tighter targeting of transfer programs toward the poor is warranted during a crisis.

Macro crises come in many varieties. A common feature is that during the crisis average purchasing power falls dramatically (otherwise they would not be macro crises). The distribution around the average, however, could move in different ways, and individual movements around the distribution could have many different patterns. Each of these factors will affect the design of povertytargeted programs, and this paper uses the literature on targeting as a base from which to analyze pro-poor programs during macro crises.

Even in "normal times," the tradeoffs inherent in balancing efficiency and distribution are involved and intricate. The literature has considered this balance primarily in the context where redistribution has efficiency costs in a second-best world with limited policy instruments. A more recent literature has, quite rightly, highlighted the efficiency gains from redistributive policies in this very same second-best world. ${ }^{3}$ However, to the extent that these are net gains-the difference between gross efficiency gains and gross costs of redistribution - the design of policy to minimize the efficiency costs of redistribution still has relevance.

A particular class of policy instruments where these issues come to the fore are programs and interventions that explicitly target the poor as an objective (at least partially). These include subsidies on a range of commodities including

\footnotetext{
${ }^{1}$ Ravi Kanbur is T.H. Lee Professor of World Affairs, International Professor of Applied Economics and Management, and Professor of Economics, Cornell University.

${ }^{2}$ For an excellent overview of the discourse, which also touches on some of the points covered in this paper, see Ravallion (2008).

${ }^{3}$ This literature has been reviewed in World Bank (2005).
} 
food, fuel, energy, and water. The subsidies can be generalized in nature, applying to rich and poor alike, with the targeting relying on consumption differences between rich and poor across commodities. Or they can be targeted only to those who satisfy criteria that identify poverty. Another class of programs, which have been present for a long time in some developing countries, but whose use has exploded in the last two decades, consists of conditional cash transfers. ${ }^{4}$ These provide cash benefits in response to some action from the beneficiary-like working on a public works site for employment schemes, keeping children in school, or attending health clinics. Sometimes, combinations of conditions are used. These programs can be further restricted to those who satisfy a poverty criterion.

The general education and health system can also be viewed as a redistributive mechanism. In fact, it has often been argued that these expenditures by the state are poorly targeted to the poor. However, reform of these systems is an issue for the long term. The general tax system can also be viewed as a redistributive instrument. Even if it is viewed only as a source of revenue for the targeted programs described above, the targeting of the tax system itself-its progressivity - will affect the targeting of government financial transfers as a whole. But again, these reforms are of a long-term nature. This paper does not focus on education and health policy or on general tax policy. The focus, rather, is on instruments for getting purchasing power into the hands of the poor from the expenditure side of government policy.

The paper proceeds as follows. First, it reviews the theory of targeting, highlighting the tradeoffs between fine targeting of programs toward the poor versus broader coverage. Second, it treats the macro shock as permanent and examines how the nature of the tradeoff changes, deriving guidelines for the use of alternative policy instruments and design of new ones. Third, it extends the insights to the case where the shock is temporary: how should this change the deployment of existing instruments during a crisis and the design of new instruments for a world of temporary, but sharp, downturns? A final section concludes.

\section{Tradeoffs in Targeting}

The modern literature on targeting goes back at least as far as Akerlof's (1978) formalization of the use of a limited number of policy instruments to pursue a poverty minimization strategy, taking into account information and incentive constraints, broadening and enriching the Mirrlees (1971) and Diamond-Mirrlees (1971) optimal taxation framework. Besley and Kanbur $(1988,1993)$ provide an account of the key conceptual elements in the theory of targeting in the context of

\footnotetext{
${ }^{4}$ For a recent review, see Fiszbein and Schady (2009).
} 
developing countries. This section lays the groundwork for the discussion of targeting during crises by examining the basic principles of targeting and identifying some of the key tradeoffs involved. ${ }^{5}$

Consider a government that has a given budget for poverty reduction, poverty being identified as the shortfall of consumption from an agreed poverty line. Suppose initially that there are no informational or administrative problems; the government can costlessly identify each person's consumption relative to the poverty line. Suppose further that there are no behavioral responses and hence no incentive effects of alternative government interventions. In such a situation, how best should the government use its budget to alleviate poverty?

The answer depends on the precise nature of the government's poverty objective (Bourguignon and Fields 1990). If, on the one hand, the objective is to minimize the "headcount ratio" - the fraction of units below the poverty linethen the answer is to start with units closest to the poverty line and to go down from there, lifting units to the poverty line until the budget runs out. If, on the other hand, the objective is to minimize the aggregate poverty gap-the sum of all the shortfalls of consumption from the poverty line-then at the margin, it does not matter who among the poor is given the transfer, since the aggregate poverty gap would be reduced by the same amount. Finally, consider a poverty objective where greater weight is given to the poorest of the poor, as in the aggregate squared poverty gap. Now the strategy is the following. Start with the poorest unit. Give this unit transfers until it reaches the level of the next poorest unit. Then give these units transfers until they are raised to the level of the next unit. And so on until the budget is exhausted. This would be the strategy to follow for all poverty measures in the Foster, Greer, and Thorbecke (1984) family of poverty measures, where the degree of poverty aversion (the "FGT alpha") is greater than one (for the squared poverty gap measure, the degree of poverty aversion is two).

This analysis is useful as a benchmark of "perfect targeting," which means giving the poor just enough to bring them up to the poverty line and avoiding leakages to the nonpoor. The total resource required for this is simply the sum of all the poverty gaps. If this amount is not available, poverty cannot be eliminated by redistribution. But even if this amount were available, it is highly unlikely that poverty could be eliminated, because perfect targeting is, of course, an ideal that is unlikely to be met in practice. As Besley and Kanbur (1993) argue, three central issues arise: information, incentives, and political economy.

The informational problem is quite simply that it is not costless to identify who is poor and who is not and to measure the precise poverty gap for each poor person. Put another way, the policy instruments available are far coarser than perfect targeting requires. At the other extreme, it may not be possible to distinguish individuals from each other at all, forcing us to make the same

${ }^{5}$ For a comprehensive review of principles and experience, see Grosh and others (2008). 
transfer to all. This "demo-grant" instrument is not very well targeted, but it is least costly in terms of informational requirements. In practice two types of instruments are available to policy makers that can bridge the gap between perfect targeting and "perfectly imperfect" targeting: indicator targeting and selftargeting.

Indicator targeting uses (more) easily observable characteristics of individuals to condition transfers, relying on the correlation between the (relatively more easily) observable attributes and (more difficult to observe, verify, and monitor) income-consumption-purchasing power. Each individual with the same value of the indicator variable (for example, area of residence, color of skin, gender, age) is treated identically, so there will be some "leakage" since some individuals in the category will be above the poverty line. But if the policy maker knows the statistical properties of the bivariate distribution between the indicator variable and consumption (say), through a representative household survey, for example, transfers to different values of the indicator variable can be modulated to achieve greater poverty reduction than could be achieved with an equal transfer to everybody. The theory of such transfers, inspired by Akerlof (1978), is worked out in Kanbur (1987) and Besley and Kanbur (1988). Essentially, the differential in transfers to different values of the indicator variable should increase as the poverty differential between them increases.

Self-targeting, in contrast, uses differences between the behavior of richer and poorer individuals-induced, in turn, by differences in preferences or in opportunity costs of time, for example. Using a poverty alleviation budget to subsidize the consumption of commodities differentially relies on differences in consumption patterns. As shown by Besley and Kanbur (1988), the key targeting indicator is the fraction of total consumption of a commodity that is accounted for by those below the poverty line. Differences in this value between two commodities govern the differential rate of subsidy between them. The opportunity cost of time can be used to self-target if the transfer is proportional (say) to time expended in getting the transfer. The most obvious example of this is a public works scheme with a given wage. Clearly, only those for whom the opportunity cost of time (earnings in alternative activity) is less than the wage will turn up to work on the site. If this is, in turn, negatively associated with poverty status, lowering the wage will tighten the poverty targeting of the transfer effected through the public works scheme. ${ }^{6}$

All of the above supposes no incentive effects of the transfer scheme itself. To see the consequences of these effects, take the case where there are no informational constraints and consider the perfect targeting scheme where every poor person is given just the transfer to get them up to the poverty line and no more. What this means is that, as the nonprogram resources of a poor person

6 The targeting properties of public works schemes have been analyzed extensively by Ravallion $(1999,2006)$. 
increase, program transfers are reduced one for one. In other words, the effective marginal tax rate is 100 percent. This removes all incentives for the poor to increase their resources (incomes, say) through their own efforts. Indeed, it removes incentives even to maintain their incomes at the levels they were before the program. In the extreme, no one in poverty would earn any incomes, and the costs of poverty elimination would increase, perhaps dramatically.

Perfect targeting implies and requires 100 percent effective marginal tax rates. This leads to a tradeoff with incentives to earn income (generate nonprogram resources). At the other extreme, the demo-grant has a 0 percent effective marginal tax rate, but it is very poorly targeted. Kanbur, Keen, and Tuomala (1994) show that, if the objective is to minimize poverty, then neither extreme is appropriate; in fact, the optimal transfer withdrawal rates on the poor - in other words, the effective marginal tax rates - are on the order of 60-70 percent. This should give a quantitative feel for how far incentive effects can pull us from the perfect targeting benchmark.

The third issue with perfect targeting of a given budget for poverty reduction arises when considering the source of the budget. To the extent that this budget comes from the operation of political economy forces within the country in question, the fact that those above the poverty line get nothing at all from perfect targeting (indeed this "zero leakage" is part of the definition of perfect targeting) may determine how much budget becomes available for this program. As proposed by Besley and Kanbur (1993) and formalized by Gelbach and Pritchett (2000), one of the costs of fine targeting may be that the total budget for poverty reduction may become smaller. ${ }^{7}$ Coarser targeting involves leakages to the nonpoor, but precisely for this reason may help to build a political coalition between the poor and the near-poor to increase the budget for the program. Hence, in Gelbach and Pritchett's telling phrase, "leakier can be better" for poverty reduction. These arguments are, of course, well rehearsed in the debates on "universalism" versus "means testing" for welfare states in rich countries. But they have particular resonance for targeting the poor in poor countries.

The above sets the frame for how the large literature on targeting, only touched on here, approaches the tradeoffs in ensuring that transfers intended for poverty reduction reach the poor. How are these tradeoffs altered when the economy undergoes a massive negative shock that reduces average incomes and purchasing power and possibly alters the income distribution in significant ways? The next section takes up the case where the shock is permanent.

\footnotetext{
7 Anand and Kanbur (1991) argue that these forces were present in the aftermath of targeting of generalized rice subsidies in Sri Lanka during the crisis of the late 1970s.
} 


\section{Tradeoffs after a Permanent Shock}

This section considers the case where the macro crisis permanently alters the distribution of income. As noted earlier, the mean of the distribution must fall, and dramatically so, for any crisis worth that label. This by itself will increase poverty if the shape of the distribution remains unchanged. But what happens to the shape of the distribution? This can be quite complex and depends on the detail of the nature of the crisis and the structure of the economy. A financial crisis may well affect upper incomes more drastically, thereby reducing overall inequality. However, if, for example, the direct effect (through export contraction) is on employment, inequality may well increase. Thus it is necessary to consider both cases-where the crisis, although reducing the mean for sure, either decreases or increases overall inequality.

Beyond the ambiguity in the change in overall inequality, the composition of the distribution can also change in intricate ways, with certain occupations, regions, and socioeconomic groupings losing more than others-perhaps some even winning as others lose heavily. If these are the groupings that are being used to target, then the macro shock, through its impact on the detailed composition of the distribution, could affect targeting tradeoffs as well. But the changes in the distribution will affect targeting tradeoffs in other ways as well. Moreover, it is expected that the crisis will, in the first instance, reduce the resources available for poverty reduction, and this will also affect the tradeoffs. Specifically, will the shock shift the balance in favor of finer targeting or away from it? This is a central policy question, since arguments are heard in both directions, and intuition and instinct pull us first one way and then the other.

Let us consider in turn the three issues highlighted in the previous sectioninformation, incentives, and political economy. Starting with the informational constraints to perfect targeting, it can be argued that it is now worth spending more resources to identify the poor and how poor they are, so as to better deploy the reduced resources toward the goal of poverty reduction. There is indeed a literature on the administrative costs of targeting, which shows that fine targeting does not come cheap. The tradeoff is now between using some more of the diminished resources to reduce "leakage" to the nonpoor and leaving less for the actual transfer. The final answer is ambiguous, depending on the precise nature of how targeting improves with greater administrative outlays and how much the needs of the poor for transfers increase with the crisis.

Turning to the use of indicator targeting as a response to informational constraints, consider the proposition that differential per capita transfers to different groups should follow the differential in poverty between those groups. A reduction in the overall budget for poverty reduction would not change this conclusion. If anything, it would strengthen it, in the sense that, when resources are tight, deviation from the rule would lead to even bigger losses in the

objective of minimizing poverty. What about changes in the underlying income 
distribution? The answer would depend very much on how poverty incidence was changed across the policy-relevant groups. If the increase in poverty was uniform, then the allocation, at least its direction, would not be affected. However, if at the other extreme the relative poverty ranking of the two groups reversed as a result of the crisis (even as poverty went up in both groups), the allocation rule would dictate a shift in priorities. Detail matters, therefore, and thus information on the impact of the crisis on poverty by salient socioeconomic groups is crucial in determining an optimal response.

For self-targeting through differential subsidy of commodity groups, the key ratio is total consumption of a commodity by the poor divided by total consumption of the commodity in the economy as a whole. A generalized reduction in incomes may change this ratio depending on the precise nature of the Engle curve for each commodity, but it is unlikely to reverse rankings across commodities. However, since poverty will have increased, poverty minimization will require that more of the available resources go to subsidize commodities where the key ratio is highest. The same will hold true if total resources available for transfer are reduced. In this sense, therefore, the crisis will require a tightening of targeting to the poor. Self-targeting through choice of wages in public works schemes will require lower wages as the total resources available fall, especially if the crisis also lowers returns to other activities and hence the opportunity cost of working at the public works site. In this sense, again, the crisis requires a tightening of the targeting regime.

Let us turn now to the tradeoffs around the incentive effects from fine targeting. As noted in the previous section, Kanbur, Keen, and Tuomala (1994) argue that the optimal, poverty-minimizing, income tax schedule implies effective marginal tax rates on the poor on the order of 60-70 percent. This is done in the Mirrlees (1971) optimal income taxation framework. It is also shown that, as the mean of the income distribution falls, the optimal marginal tax rate on the poor increases. The intuition behind this is that, since the poor are now poorer, there is a greater pull to provide support to the poorest of the poor. The budget constraint, however, requires that this be "clawed back" faster as incomes increase-hence the higher marginal tax rates even on the poor themselves. A similar intuition holds for the case where, holding mean constant, overall inequality of the underlying income distribution increases. ${ }^{8}$ The poor are now poorer and require greater support, necessitating higher marginal tax rates to meet the budget constraints. These higher marginal tax rates will, of course, have incentive effects on the poor, but this is traded off against the need for finer targeting to support the very poorest, since the crisis has made them even poorer. The argument runs in reverse if inequality falls during the crisis. However, for a crisis that increases inequality as well as lowers the mean, the

${ }^{8}$ A formal analysis is provided in Kanbur and Tuomala (1995). 
theory of targeting with incentive effects also suggests a tightening of the targeting toward the poorest of the poor.

Consider now the political economy dimensions of targeting. As noted earlier, fine targeting, which by definition excludes the near poor and the nonpoor, makes the best use of available resources for poverty minimization, but reduces political support for the transfer program and hence the total resources available for the program. The informational arguments tilt the balance in favor of fine targeting in a crisis, and it can also be shown that incentive effects of fine targeting do not overturn this conclusion. But fine targeting tends to reduce the total available resources for the transfer program, exactly at the time that resources have been reduced as a result of the crisis. Indeed, on this reasoning, there is the danger of a downward spiral as fewer resources lead to finer targeting, leading to fewer resources, further tightening of targeting, and so on. When overall resources fall, and needs increase as the result of a tightening, the political economy arguments thus favor a loosening, not a tightening, of targeting if the objective is to maximize transfers to the poorest in a time of heightened constraints. These arguments thus align with popular calls that the well off should share the burden of the crisis and that "we are all in this together."

What, then, does the theory of targeting have to say about targeting transfers to the poor at a time of macro crisis? The answer depends very much on whether the targeting regime or the resources are exogenous. If the resources are independent of the targeting regime, the case for finer targeting is strong (although not unequivocal), even when incentive effects are taken into account. However, if the targeting regime can be picked by the technocrats, say, and the resources are then decided by the domestic political economy, finer targeting is not necessarily the answer-in fact, a case may be made for looser targeting. In either case, the argument for additional external resources is strong, not only to replenish reduced domestic resources for poverty reduction, but also to prevent a downward spiral of finer and finer targeting with fewer and fewer resources.

\section{Temporary Shocks}

The previous discussion treats the macro shock as permanent, so that the existing theory of targeting "in comparative static manner" is simply applied to the new situation with a different distribution of income and reduced resources for poverty reduction. But what if the macro shock is, as one would hope, temporary? This leads to several considerations that are not present in the permanent shock scenario.

The literature on poverty has highlighted the risk and vulnerability associated with poverty, the costs of this for the poor, and the central role of safety nets in addressing these problems. The focus of this large literature is on 
idiosyncratic shocks, and risk sharing (or lack thereof) among the poor. ${ }^{9}$ Macro crises, however, are not idiosyncratic; they are systemic shocks that affect everybody. There may be some scope for risk sharing if the impact of the crisis is to benefit some poor, while hurting others, but this is not the scenario uppermost in policy makers' minds when they think of macro shocks. In the present context, the shocks considered here are systemic, not idiosyncratic, ones.

If the macro shock were truly temporary, in the sense that an equal and opposite shock (in the appropriate sense) will eventually restore the economy to a long-run average path, then there is, in principle, no need to change transfers policy at all. The same amount of resources, and the same targeting regime, that applies to the long-run average state of the economy could apply in good times and in bad times, using appropriate saving and borrowing by the government for smoothing.

But there are (at least) two arguments in the literature questioning whether a temporary shock is in fact all that temporary. First, temporary shortfalls in consumption for the poor translate into long-run consequences for economic and human development, so long-run economic and social well-being of the poor tracks the negative shock; it is not counteracted to an equal and opposite extent by an equal and opposite positive shock. Second, government actions to address the temporary shock cannot be reversed when the shock is reversed, leaving an inappropriate redistributive structure in place for the long run. The first suggests moving aggressively to address the temporary shock-essentially as though it were a permanent shock. The second suggests caution and moving only on reversible policy changes, even if this means some of the temporary shock is not addressed and has long-term consequences.

With this background, let us think through the case for finer targeting with a temporary (but severe) negative macro shock. The above structure of argument allows us to assess a common piece of advice to policy makers: "In a macro crisis do not expand programs, like generalized subsidies, that are not well targeted to the poor. These are not an efficient way of reaching the poor, and when the crisis passes you will be stuck with a targeting regime that will be inefficient in terms of poverty alleviation." It should be clear that the validity of this advice depends on the detailed specification of and interaction between the purely technical aspects of targeting and its political economy dimensions.

With the shock (temporary but with long-term consequences for the poor), suppose finer targeting is indeed suggested by the non-political economy analysis, as discussed in the previous section: with reduced resources and greater needs, greater support for the poorest in difficult times requires the support to be clawed back rapidly. In this view there is certainly not a case for loosening the targeting. And, it is further argued, loosening of the targeting will be difficult to reverse when the economy returns to its long-term path because of political

${ }^{9}$ For a representative selection of papers in this literature, see Dercon (2004). 
economy pressures. But this second part of the argument reveals a conceptual problem in the whole sequence, because the political economy dimension has a logic of its own, into which irreversibility plays in a nuanced way.

If changes in the targeting regime are indeed irreversible (or at least difficult to reverse), and the political economy of resource mobilization for poverty alleviation transfers plays out conditional on the targeting regime, then the "leakier is better" analysis suggests that poverty reduction has nothing to fear from a move toward looser targeting in the wake of a crisis. Looser targeting should help to increase resources for poverty alleviation. If anything, moving toward finer targeting is problematic. Finer targeting, if irreversible, will lead to lower overall resources for antipoverty transfers in the future and perhaps even in the near term. Less fine targeting with fixed resources will be less efficient for poverty reduction, but, if irreversible, it will lead to more resources used for the antipoverty transfers in the future and perhaps even immediately. Thus the policy advice to move to finer targeting to weather temporary but severe negative shocks is not necessarily valid if the political economy dimensions of irreversibility of the targeting regime are taken into account.

However, one type of policy move can be unequivocally supported in the face of temporary shocks: this is to invest in removing the irreversibilities that led to the dilemmas in the first place. Thus improving income and consumptionsmoothing instruments for the poor, so that negative shocks do not have longterm effects on them, is an obvious answer. There is a large literature on this, and it is not discussed further here (see Dercon 2004). Rather, the focus is on improving flexibility through the operation of various income transfer programs. There are both technocratic and political economy dimensions to this.

To illustrate the issues involved, consider a type of program often used to help the poor in crises: public works schemes. Specifically, consider India's National Rural Employment Guarantee Act, which aims to guarantee 100 days of employment a year to rural households (at the local minimum wage). ${ }^{10}$ When rural employment falls, this program is meant to kick in to shore up incomes. It is flexible in design in the sense that employment is offered to all those who show up at the wage; thus the program can be scaled up or scaled down as employment conditions improve. But there are two key questions. First, what is being done with the labor employed? Second, where will the resources come from to finance an expansion of the program?

Assessments of public works schemes show that the value of assets created is a key component of the benefit of these schemes-indeed it is argued that, in many cases, it is this value that tips the cost-benefit into supporting the program as public expenditure. ${ }^{11}$ It is also recognized that a central design feature determining whether valuable assets are created is the presence or otherwise of a

\footnotetext{
${ }^{10}$ An introduction to this is provided in Basu, Chau, and Kanbur (2007).

11 Ravallion (1999). Murgai and Ravallion (2005) argue that the poverty impact of the National Rural Employment Guarantee Act depends crucially on the value of assets created.
} 
"shelf of projects" ready to go when demand for employment increases as the result of a crisis. Without these, the workers are indeed "digging holes to fill them up again." While still useful as a form of targeting of transfers (recall the opportunity cost arguments made in the previous section), clearly much more could be achieved. But this requires planning before the crisis and expending resources to prepare and update projects, which will only be activated as necessary. This investment in flexibility is well worth making, but it is one that standard assessment systems-for example, those of donors-do not seem to appreciate and finance. To expend resources to prepare projects that may not be implemented immediately is not something that donor systems are designed to incorporate. This is also a problem for community-driven participatory project design. It is not easy to explain to local communities why the projects that they have spent so much time helping to design, and for which there is immediate need, are to be held off until there is an employment crisis. But these are hurdles, at the local, national, and international levels, that will have to be overcome to increase flexibility of public works schemes and thus to improve their role in targeting transfers during crises.

The above supposes that the resources available (wage costs of increased employment and complementary nonlabor costs of the projects) will increase as the employment needs increase in the wake of a crisis. If the resources do not increase, employment will be rationed, with no improvement in poverty and perhaps even a worsening if rationed employment is allocated to favor the better off. But how can an increase in resources be assured? In the Indian case, the device used is that of a justiciable guarantee. In effect, the polity makes the central government and the state governments liable in law to provide the employment. If they do not, they can be taken to court. It is hoped that the costs to government of this action by public interest litigation will be sufficiently high to ensure that government makes sufficient resources available. In other words, the political economy is guided toward providing the resources by raising the costs to key actors of not doing so.

At least two questions can be raised regarding this method of achieving flexibility and ensuring that resources do flow to the poor in a crisis. First, it is difficult to monitor the guarantee. Ground-level officials have myriad ways of discouraging employment applicants (for example, by holding the public works projects far from villages). While some of these can be accounted for in law (for example, requiring that the public works be no farther than a certain distance from the village of the applicant), there is residual discretion that simply cannot be addressed. ${ }^{12}$ Second, it relies on the fact that being taken to court is costly for officials and that they and the public will abide by court judgments. Increased and continued use of courts in this way may well reduce the effectiveness of this device over time.

\footnotetext{
12 Basu, Chau, and Kanbur (2009) present a theory of employment guarantees where credibility of
} the guarantee is center stage. 
A similar exercise can be conducted for each transfer program, asking how its technical design can be made more flexible so that, with a given degree of targeting, it can be expanded or contracted easily, the flexibility being both a technical issue and one of political economy. With this background for individual programs, the overall set of programs as a whole can be seen as the instrument for helping the poor during a crisis, with reallocation of resources across programs as well as changes in individual programs as the needs of the crisis become apparent. ${ }^{13}$

Finally, as has been noted at several points in this and the previous sections, external resources can help to ease the many painful tradeoffs that policy makers face during crises. Over the long term, they can help in putting in place more flexible transfer programs that can move quickly to adjust as crises erupt. In the short term, they can reduce the need for looser targeting, or the use of courtbacked guarantees, to generate greater resources domestically. The looser targeting made possible by greater external resources can help to reduce the informational and incentive costs of fine targeting. ${ }^{14}$

\section{Conclusions}

A central question for policy makers concerned with helping the poor through a macro crisis is how to target scarcer resources at a time of greater need. Technical arguments suggest that finer targeting, through tightening individual programs or reallocating resources toward more tightly targeted programs, uses resources more efficiently for poverty reduction. These arguments survive even when the greater informational costs and the incentive effects of finer targeting are taken into account. But political economy arguments suggest that finer targeting will end up with fewer resources allocated to that program and that looser targeting, because it knits together the interests of the poor and the near-poor, may generate greater resources and hence be more effective for poverty reduction despite being "leakier." Overall, the policy advice to avoid more loosely targeted programs during crises needs to be given with considerable caution. However, the advice to design transfer systems with greater flexibility, in the technical and the political economy senses, is strengthened by the arguments presented here. The case for external assistance - to design flexible transfer systems ex ante and to relieve the painful tradeoffs in targeting during a crisis - is also shown to be strong.

13 The argument for treating the collectivity of transfer programs as a system is made in Kanbur (2009).

${ }^{14}$ Implications for donors like the World Bank are developed further in Kanbur (2009). 


\section{References}

Akerlof, George. 1978. "The Economics of 'Tagging' as Applied to the Optimal Income Tax, Welfare Programs, and Manpower Planning." American Economic Review 68 (1): 8-19.

Anand, Sudhir, and Ravi Kanbur. 1991. "Public Policy and Basic Needs Provision in Sri Lanka." In The Political Economy of Hunger. Vol. 3: Endemic Hunger, ed. Jean Drèze and Amartya Sen, 59-92. Oxford: Clarendon Press.

Basu, Arnab, Nancy Chau, and Ravi Kanbur. 2007. “The National Rural Employment Guarantee Act of India, 2005." In The Oxford Companion to Economics in India, ed. Kaushik Basu. New York: Oxford University Press.

—. 2009. “A Theory of Employment Guarantees: Contestability, Credibility, and Distributional Concerns." Journal of Public Economics 93 (3-4, April): 482-97.

Besley, Timothy, and Ravi Kanbur. 1988. "Food Subsidies and Poverty Alleviation." Economic Journal 98 (392, September): 701-19.

—_ 1993. "The Principles of Targeting." In Including the Poor, ed. Michael Lipton and Jacques van der Gaag, 67-90. Washington, DC: World Bank.

Bourguignon, François, and Gary Fields. 1990. "Poverty Measures and AntiPoverty Policy." Recherches Economique de Louvain 56 (3-4): 409-28.

Dercon, Stefan, ed. 2004. Insurance against Poverty. New York: Oxford University Press.

Diamond, Peter, and James Mirrlees. 1971. "Optimal Taxation and Public Production II: Tax Rules." American Economic Review 61 (3, pt. 1, June): 26178.

Fiszbein, Ariel, and Norbert Schady. 2009. Conditional Cash Transfers for Attacking Present and Future Poverty. Policy Research Report. Washington, DC: World Bank, Development Research Group.

Foster, James, Joel Greer, and Erik Thorbecke. 1984. “A Class of Decomposable Poverty Measures." Econometrica 52 (3, May): 761-66.

Gelbach, Jonah, and Lant Pritchett. 2000. "Indicator Targeting in a Political Economy: Leakier Can Be Better." Journal of Policy Reform 4 (2): 113-45.

Grosh, Margaret, Carlo del Ninno, Emil Tesliuc, and Azedine Ouerghi. 2008. For Protection and Promotion: The Design and Implementation of Effective Safety Nets. Washington, DC: World Bank.

Kanbur, Ravi. 1987. "Measurement and Alleviation of Poverty: With an Application to the Impact of Macroeconomic Adjustment." IMF Staff Papers 34 (March): 60-85. 
— 2009. "Systemic Crises and the Social Protection System: Three Proposals for World Bank Action." Working Paper 235. Cornell Food and Nutrition Program, Cornell University, Ithaca, NY. http://www.kanbur.aem.cornell. edu/papers/SystemicCrisesAndTheSocialProtectionSystem.pdf.

Kanbur, Ravi, Michael Keen, and Matti Tuomala. 1994. "Labor Supply and Targeting in Poverty Alleviation Programs." World Bank Economic Review 8 (2): 191-211.

Kanbur, Ravi, and Matti Tuomala. 1995. "Inherent Inequality and the Optimal Graduation of Marginal Tax Rates." Scandinavian Journal of Economics 96 (2): 275-82.

Mirrlees, James A. 1971. "An Exploration in the Theory of Optimum Income Taxation." Review of Economic Studies 38 (114): 175-208.

Murgai, Rinku, and Martin Ravallion. 2005. “Employment Guarantee in Rural India: What Would It Cost and How Much Would It Reduce Poverty?" Economic and Political Weekly, July 30, pp. 3450-55.

Ravallion, Martin. 1999. “Appraising Workfare.” World Bank Research Observer 14 (1): $31-48$.

—. 2006. "Transfers and Safety Nets in Poor Countries: Revisiting the Tradeoffs and Policy Options." In Understanding Poverty, ed. Abhijit Banerjee, Roland Benabou, and Dilip Mookerjee. Oxford: Oxford University Press.

—. 2008. "Bailing out the World's Poorest." Policy Research Working Paper 4763. World Bank, Washington, DC.

World Bank. 2005. World Development Report 2006: Equity and Development. New York: Oxford University Press. 



\section{Eco-Audit}

\section{Environmental Benefits Statement}

The Commission on Growth and Development is committed to preserving endangered forests and natural resources. The World Bank's Office of the Publisher has chosen to print these Working Papers on 100 percent postconsumer recycled paper, processed chlorine free, in accordance with the recommended standards for paper usage set by Green Press Initiative-a nonprofit program supporting publishers in using fiber that is not sourced from endangered forests. For more information, visit www.greenpressinitiative.org. The printing of all the Working Papers in this Series on recycled paper saved the following:

\begin{tabular}{|c|c|c|c|c|}
\hline Trees $^{*}$ & Solid Waste & Water & Net Greenhouse Gases & Total Energy \\
\hline 48 & 2,247 & 17,500 & 4,216 & 33 mil. \\
\hline $\begin{array}{c}{ }^{*} 40 \text { inches in } \\
\text { height and 6-8 } \\
\text { inches in diameter }\end{array}$ & Pounds & Gallons & Pounds CO2 Equivalent & BTUs \\
\hline
\end{tabular}




\section{The Commission on Growth and Development Working Paper Series}

57. From Growth Theory to Policy Design, by Philippe Aghion and Steven Durlauf, April 2009

58. Eight Reasons We Are Given Not to Worry about the U.S. Deficits, by Jeffrey Frankel, April 2009

59. A New Bretton Woods? by Raghuram G. Rajan, June 2009

60. Climate Change and Economic Growth, by Robert Mendelsohn, June 2009

61. Public Finance and Economic Development: Reflections based on the Experience in China, by Roger H. Gordon, July 2009

62. Greenhouse Emissions and Climate Change: Implications for Developing Countries and Public Policy, by David Wheeler, July 2009

63. What Do We Know about Monetary Policy that Friedman Did Not Know? by Charles Wyplosz, July 2009

64. Climate Change, Mitigation, and Developing Country Growth, by Michael Spence, August 2009

65. Growth after the Crisis, by Dani Rodrik, September 2009

66. Macro Crises and Targeting Transfers to the Poor, by Ravi Kanbur, April 2010

\section{Forthcoming Papers in the Series:}

Financial Crisis and Global Governance: A Network Analysis, by Andrew Sheng (May 2010)

Crisis Transmission to Emerging Markets: The Financing Challenge, by Mario I. Blejer (May 2010) 
A central question for policy makers concerned with helping the poor through a macro crisis is how to target scarcer resources at a time of greater need. Technical arguments suggest that finer targeting, through tightening individual programs or reallocating resources towards more tightly targeted programs, uses resources more efficiently for poverty reduction. These arguments survive even when the greater informational costs and the incentive effects of finer targeting are taken into account. But political economy arguments suggest that finer targeting will end up with fewer resources allocated to that program, and that looser targeting, because it knits together the interests of the poor and the nearpoor, may generate greater resources and hence be more effective for poverty reduction despite being "leakier." Overall, the policy advice to tighten targeting and to avoid more loosely targeted programs during crises needs to be given with considerable caution. However, the advice to design transfer systems with greater flexibility, in the technical and the political economy senses, is strengthened by the arguments presented here. The case for external assistance - to design flexible transfer systems ex ante and to relieve the painful tradeoffs in targeting during a crisis - is also shown to be strong.

Ravi Kanbur, T.H. Lee Professor of World Affairs, International Professor of Applied Economics and Management, and Professor of Economics, Cornell University

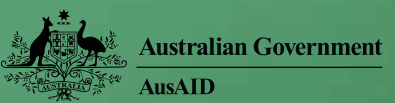

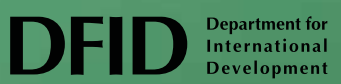

Dutch Ministry

of Foreign Affairs

THE WILLIAM AND FLORA

H E W L E T T

FOUNDATION

Sida

www.growthcommission.org

contactinfo@growthcommission.org
Commission

on Growth and

Development

Montek Ahluwalia

Edmar Bacha

Dr. Boediono

Lord John Browne

Kemal Derviş

Alejandro Foxley

Goh Chok Tong

Han Duck-soo

Danuta Hübner

Carin Jämtin

Pedro-Pablo Kuczynski

Danny Leipziger, Vice Chair

Trevor Manuel

Mahmoud Mohieldin

Ngozi N. Okonjo-Iweala

Robert Rubin

Robert Solow

Michael Spence, Chair

Sir K. Dwight Venner

Hiroshi Watanabe

Ernesto Zedillo

Zhou Xiaochuan

The mandate of the

Commission on Growth

and Development is to

gather the best understanding

there is about the policies

and strategies that underlie

rapid economic growth and

poverty reduction.

The Commission's audience

is the leaders of developing

countries. The Commission is

supported by the governments

of Australia, Sweden, the

Netherlands, and United

Kingdom, The William and

Flora Hewlett Foundation,

and The World Bank Group. 